\title{
Can Patients with Diabetes Detect their own Eating Disorder? The Need for A Better Understanding of Eating Pathology in Diabetes
}

\author{
Cynthia Gagnon ${ }^{1}$, Annie Aimé ${ }^{*}$ and Claude Bélanger ${ }^{1}$ \\ ${ }^{1}$ Université du Québec à Montréal, Canada \\ ${ }^{2}$ Université du Québec en Outaouais, Canada
}

Submission: April 10, 2017; Published: July 31, 2017

*Corresponding author: Annie Aimé, Département de psychoéducation et de psychologie, Université du Québec en Outaouais, Canada, Tel: 450530-7616; Email: annie.aime@uqo.ca

\begin{abstract}
Some authors have suggested that patients with diabetes may hardly detect a comorbid eating disorders. Unfortunately, not doing so can negatively impact treatment and lead to several unwanted medical complications and psychological problems. Moreover, when a comorbid eating disorder in a patient with diabetes is not treated, it tends to be recurrent and persistent over time. This study aims to compare patient's own report of eating problems to a diagnosis established with the Eating Disorders Examination Questionnaire-6. A total of 624 patients with diabetes (type 1 diabetes=137; type 2 diabetes=487) participated to an online survey. The results provide support to the idea that people with diabetes may not adequately evaluate whether they have a comorbid ED or not. While many participants reported eating problems that did not meet an ED diagnosis, others thought they had no eating problems but their self-reported symptoms met the criteria for an ED diagnosis. People with type 2 diabetes were more likely to report eating problems when there was no ED diagnosis and people with type 1 diabetes were more at risk of denying eating problems when they presented symptoms associated with an ED. These results must be understood in light of the treatment particularities of each type of diabetes: weight management is strongly recommended in people with type 2 diabetes and monitoring of eating is considered essential for those with type 1 diabetes. These patients' difficulty to detect a comorbid ED should be taken seriously given that it may considerably impair their diabetes management.
\end{abstract}

Keywords: Diabetes; Eating disorders; Diagnosis; Self-reported eating problems

Abbreviations: ED: Eating Disorders; PWD: Patients With Diabetes; T1D: Type 1 Diabetes; T2D: Type 2 Diabetes

\section{Introduction}

Recent research suggests that health professionals might find difficult to detect eating disorders (ED) among patients with diabetes (PWD) [1]. Moreover, the clinician's diagnosis impression may differ from the patients' own perception of their eating pathology [2]. In fact, according to Allan (2015), patients with type 1 diabetes' (T1D) definition and conception of disordered eating behaviours doesn't correspond to the psychiatric nosography suggested in the Diagnostical and Statistical Manual of Mental Disorders [3]. More precisely, T1D patients who believe they have an eating disorder (ED) do not necessarily present a symptomatology that meets the diagnosis criteria of specific eating disorders such as anorexia, bulimia, or binge eating disorder [2]. For those who receive an ED diagnosis, bulimia, binge eating disorder and ED not otherwise specified have been found to be the most prevalent diagnosis [4]. However, T1D patients themselves do not feel they have bulimia since they do not consider insulin omission as a compensatory behaviour associated to ED. To qualify their eating pathology, they instead tend to refer to a non-classified eating pathology called "diabulimia" [2]. This implies that the detection of ED in T1D patients is problematic and often doesn't match the ED they are diagnosed with. Such detection problem and lack of recognition can lead to an inadequate management and treatment of eating disorders symptoms in PWD. By not seeking and receiving treatment for an ED, they expose themselves to deleterious medical (e.g. bad glycemic control [5], elevated BMI $[4,6]$ higher risk of retinopathy [7], nephropathy [8], neuropathy [6], cardiovascular problem [6], ketoacidosis [6]) and psychological (e.g. higher anxious [9] and depressive [10,11], symptoms, lower self-esteem [12] and self-directiveness [5], such as wishful thinking and self-blame [13], and perfectionism trait [8]) consequences. Furthermore, the impact on diabetic treatment can be long lasting as ED tend to be recurrent and persistent over time [14]. Although up to $40 \%$ of patients with type 2 diabetes (T2D) report eating problems [15], no study to our knowledge has examined the detection of ED among these 


\section{Current Research in Diabetes \& Obesity Journal}

patients, thus leaving unanswered the question as to whether T2D patients experience the same difficulties as T1D patients to detect and recognize a comorbid ED. This study aims at assessing ED in patients with either type of diabetes and at comparing their own report of eating problems to a diagnosis established with a valid measure of ED. A total of 624 participants diagnosed with diabetes and aged 17 to 84 years old were recruited to participate in a larger study focusing on the French validation of the Diabetes Eating Problem Survey-Revised (see Gagnon et al. [16] for a more detailed description of the study sample and procedure). Among the participants, 137 individuals stated that they had a T1D and 487 declared having a T2D. Their self- reported body mass index (BMI $=\mathrm{kg} / \mathrm{m} 2)$ [17] distribution is as follows: $1 \%$ of people with T1D were underweight, $41 \%$ were of normal weight, 39\% were overweight and 19\% were obese (Table 1). In people with T2D, none were underweight, 14\% were of normal weight, $27 \%$ were overweight and 58\% were obese. Participants were asked if they considered having eating problems. They also filled in the diagnosis items of the Eating Disorders Examination Questionnaire-6 (EDEQ-6) [18], which is frequently used to assess the presence and frequency of core eating behaviours involved in the diagnosis of ED (e.g. binge eating, fasting, vomiting, exercising excessively, taking laxatives and diuretics) as per the DSM-5 criteria [3].

Table 1: Objective BMI, self-reported eating problems, and eating disorders diagnosis according to the participants answers on the EDE-Q6.

\begin{tabular}{|c|c|c|}
\hline & Type 1 & Type 2 \\
\hline & $\mathrm{N}(\%)$ & $\mathrm{N}(\%)$ \\
\hline \multicolumn{3}{|c|}{ BMI } \\
\hline Underweight (lowerthan 18.5) & $1(0.75)$ & $1(0.75)$ \\
\hline Normal weight (18.5 to 24.9 ) & $55(41.35)$ & $55(41.35)$ \\
\hline Overweight (25 to 29.9) & $52(39.10)$ & $52(39.10)$ \\
\hline Obese class 1 (30 to 34.9 ) & $16(12.03)$ & $16(12.03)$ \\
\hline Obese class 2 (35 to 39.9 ) & $5(3.76)$ & $5(3.76)$ \\
\hline Morbid obesity class 3 (over 40 ) & $4(3.01)$ & $4(3.01)$ \\
\hline Total & 133 & 479 \\
\hline \multicolumn{3}{|c|}{ Self-report eating problems } \\
\hline Yes & $24(17.52)$ & $260(53.39)$ \\
\hline No & $113(82.48)$ & $227(46.62)$ \\
\hline Total & 137 & 487 \\
\hline \multicolumn{3}{|c|}{ Eating disorders according to the EDE-Q6 } \\
\hline Anorexia Nervosa & - & $1(0.21)$ \\
\hline Bulimia Nervosa & $4(2.92)$ & $13(2.67)$ \\
\hline Binge Eating Disorder & $14(10.22)$ & $101(20.74)$ \\
\hline Total & 18 & 115 \\
\hline
\end{tabular}

Table 2: Concordance between self-reported of eating problems and ED diagnosis according to the EDE-Q6.

\begin{tabular}{|c|c|c|c|}
\hline \multirow{2}{*}{} & \multirow{2}{*}{ Self-reported eating problems } & \multicolumn{2}{|c|}{ Eating Disorders Diagnosis According to the EDE-Q6 } \\
\cline { 3 - 4 } & & Yes & No \\
\cline { 3 - 4 } & & $\mathbf{n}(\%)$ & \\
\hline Type 1 and type 2 diabetes & & & $182(29.17 \%)$ \\
\hline & Yes & $31(4.97 \%)$ & $309(49.52 \%)$ \\
\hline Nype 1 diabetes & & & $15(10.95 \%)$ \\
\hline & Yes & $9(6.57 \%)$ & $104(75.91 \%)$ \\
\hline Type 2 diabetes & No & $9(6.57 \%)$ & \\
\hline & Yes & & $167(34.29 \%)$ \\
\hline
\end{tabular}




\section{Current Research in Diabetes \& Obesity Journal}

As can be seen in Table 1, 45.52\% of the participants reported that they had eating problems: respectively, $17.52 \%$ of people with T1D and 53.39\% of people with T2D reported such problems. In contrast, the participants' answers on the EDE-Q6 suggested that $13 \%$ of people with T1D and $24 \%$ of people with T2D had an ED. More precisely, according to the EDE-Q6, 87\% of people with T1D did not have an ED, 10\% had BED, 3\% had bulimia, and none had anorexia nervosa. In people with T2D it was observed that $76 \%$ did not have and ED, $21 \%$ had BED, $3 \%$ bulimia and $0.2 \%$ anorexia nervosa. Among the participants who considered having eating problems, the proportion of those who could not be diagnosed with an ED according to the EDE-Q6 was higher than the one of those who met the criteria for an ED. As seen in Table 2, this was found in both types of diabetes. However, T2D patients were more likely than T1D patients to report eating problems that did not encounter ED diagnosis criteria $(\chi 2(1)=$ 40.291, p <.001). T1D patients who met ED diagnosis criteria were for their part significantly more likely than T2D patients to deny having any eating problem $(\chi 2(1)=8.297, p<.05)$. In fact, people with T2D were 5.82 times more likely than people with T1D to think they had eating problems while they did not have an ED diagnosis and T1D patients were 4.23 times more at risk of not reporting eating problems when they did in fact met the diagnosis criteria for ED according to the EDE-Q6.

\section{Conclusion}

Results from this study reveal that close to half of the PWD confide in having eating problems. However, for the majority of them, the DSM- 5 criteria for an ED are not met. The most frequent ED diagnosis that was found in both T1D and T2D patients is binge-eating disorder, followed by bulimia nervosa. Anorexia nervosa was found in only one T1D participant. Interestingly, many participants believed they had eating problems but a closer evaluation, based on their self-reported symptomatology and the DSM-5 criteria, did not indicate so. This is especially true for T2D participants, with more than a third of them reporting eating problems that did not seem to be severe enough to meet ED diagnosis criteria. On the contrary, a small proportion of the participants did not report any eating problems while their responses to the diagnosis items of the EDE-Q6 suggest they have an ED. This tendency to under-report eating problems was more likely to be observed in T1D than in T2D participants. Taken together, these findings provide further support to the suggestion of Allan [2], who advances that detecting and recognizing a comorbid ED, can be difficult for PWD.

In people with $\mathrm{T} 2 \mathrm{D}$, the tendency to report eating problems in the absence of an ED could be partly explained by a higher body mass index. In fact, over three quarter of the T2D patients were either overweight or obese. This weight condition implies that they are frequently reminded about the necessity to pay close attention to their eating in order to lose weight [19].The therapeutic approach in the context of diabetes management, especially for those with T2D, focuses on eating control, weight management [19], weight measurement [20] and a loss of 5\% to $7 \%$ of the actual weight [21]. In this context, diabetes patients can understand that they have an eating problems that needs to be treated. Additionally, as their feeling of satiety might be altered by their diabetic medication [22] losing weight can be quite a challenge and, when realizing they are unable to do so, they may further believe they have eating issues resembling those found in ED. Thus, T2D patients may confound weight management problems with eating problems and some psychoeducation about ED could be beneficial for them in order to better understand the symptoms of ED and better evaluate their likelihood of really having an ED. On the contrary, approximately 5\% of PWD don't think they have eating problems while the EDE-Q6 suggests they have one. This was significantly more likely to be observed in T1D patients, which is in line with Allan's results [2]. Yet, in Allan's study [2] a much higher proportion (38.8\%) of people with T1D thought they had an ED diagnosis while they did not have one. This difference in proportion between both studies might be explained by the formulation of the question that was asked in the current study: this question focused on the participants' perception of having eating problems and not precisely on whether they believed they had an ED diagnosis. Also, participants in Allan's [2] study were recruited through a registered charity for PWD and ED - Diabetics with Eating Disorders (DWED) - while the participants in the current study were recruited in a registered charity for PWD only-Diabetes Quebec. This implies that participants in Allan's study [2] were already concerned with having an ED, which was not the case in this study. Notwithstanding these differences, Allan's [2] results and the one obtained in the current study are alarming as they imply that diabetes treatment management can be impaired by the absence of ED acknowledgement. If PWD are unaware of or deny having an ED, they are strongly at risk of developing harmful and even fatal medical complications and to endure long lasting and persistent eating problems [14].

Based on this study results, it seems that providing PWD with information about EDs and about the fact that the eating restrictions inherent to diabetic management can lead to ED appears very relevant. In fact, not only PWD but also health professionals working with them need to develop a more thorough understanding of how eating problems and disorders are experienced by PWD and of their impact on diabetes management. Standard guidelines about ED's definition and assessment in the context of diabetes could thus be beneficial for clinical practice. As such, a more systematic evaluation and monitoring of eating habits and symptoms seems important given that PWD are not able to detect themselves whether or not they have an ED. Although the EDE-Q6 can't be used alone for establishing and ED diagnosis, it shows good agreement with the diagnosis interview [21] and thus could represent a good tool to assess eating pathology in PWD. Along with it, other measures such as the Diabetes Eating Problem Survey-Revised (DEPS-R) [23] could be considered. 


\section{Current Research in Diabetes \& Obesity Journal}

\section{References}

1. Tierney S, Deaton C, Whitedhead J (2008) Caring for people with type 1 diabetes mellitus engaging in disturbed eating or weight control: a qualitative study of practitioners attitudes and practices. J Clin Nurs 18(3): 384-390.

2. Allan JA (2015) Understanding poor outcomes in women with type 1 diabetes and eating disorders. Journal of Diabetes Nursing 19(3) : 99103

3. American Psychological Association [APA] (2013) Manuel diagnostique et statistique des trouble mentaux: DSM-5. Washington, USA, P. 1146.

4. Custal N, Arcelus J, Agüera Z, Bove FI, Wales J, et al. (2014) Treatment outcome of patients with comorbid type 1 diabetes and eating disorders. BMC Psychiatry 14: 140.

5. Wilson CE, Smith EL, Coker SE, Hobbis I CA, Acerini CL (2015) Testing an integrated model of eating disorders in paediatric type 1 diabetes mellitus. Pediatric diabetes, 16(7): 521-528.

6. Grylli V, Hafferl Gattermayer A, Wagner G, Schober E, Karwautz A (2005) Eating disorders and eating problems among adolescents with type 1 diabetes: Exploring relationships with temperament and character. Journal of pediatric psychology 30(2): 197-206.

7. Rydall AC, Rodin GM, Olmsted MP, Devenyi RG, Daneman D (1997) Disordered eating behavior and microvascular complications in young women with insulin-dependent diabetes mellitus. N Engl J Med 336(26): 1849-1854.

8. Colton PA, Olmsted MP, Wong H, Rodin GM (2015) Eating disorders in individuals with type 1 diabetes: Case series and day hospital treatment outcome. European Eating Disorders Review 23(4): 312-317.

9. Takii M, Uchigata Y, Nozaki T, Nishikata H, Kawai K, et al. (2002) Classification of type 1 diabetic females with bulimia nervosa into subgroups according to purging behavior. Diabetes Care 25(9): 15711575.

10. Bächle C, Lange K, Stahl Pehe A, Castillo K, Scheuing N, et al. (2015) Symptoms of eating disorders and depression in emerging adults with early-onset, long-duration type 1 diabetes and their association with metabolic control. PLoS One 10(6): e0131027.

11. Takii M, Komaki G, Uchigata Y, Maeda M, Omori Y, et al. (1999] Differences between bulimia nervosa and binge-eating disorder in females with type I diabetes: The important role of insulin omission. Journal of Psychosomatic Research 47(3): 221-231.

12. Maharaj SI, Rodin GM, Olmsted MP, Connolly JA, Daneman D (2003) Eating disturbances in girls with diabetes: The contribution of adolescent self-concept, maternal weight and shape concerns and mother-daughter relationships. Psychological Medicine: A Journal of Research in Psychiatry and the Allied Sciences 33(3): 525-539.

13. Grylli V, Hafferl Gattermayer A, Wagner G, Schober E, Karwautz A (2005) Eating disorders and eating problems among adolescents with type 1 diabetes: Exploring relationships with temperament and character. Journal of pediatric psychology 30(2): 197-206.

14. Colton PA, Olmsted MP, Daneman D, Farquhar JC, Wong H, et al (2015) Eating disorders in girls and women with type 1 diabetes: A longitudinal study of prevalence, onset, remission, and recurrence. Diabetes Care 38(7) : 1212-1217.

15. Meneghini LF, Spadola J, Florez H (2006) Prevalence and associations of binge eating disorder in a multiethnic population with type 2 diabetes. Diabetes Care 29(12): 2760.

16. Gagnon C, Aimé A, Bélanger C (2017) Psychometric properties of the French Diabetes Eating Problem Survey-Revised (DEPS-R). BAOJ Diabetes: 3(2): 1-8.

17. World Health Organization [WHO] (2017) Global database on body mass index: BMI classification. Retrieved from http://apps.who.int/ bmi/index.jsp?introPage=intro_3.html.

18. Fairburn CG (2008) Cognitive behavioral therapy and eating disorders. NY The Guilford Press, USA.

19. American Diabetes Association [ADA] (2016a) Standard in medical care in diabetes-2016. The Journal of Clinical and Applied Research and Education 39(1): S1-S112.

20. Treasure J, Kan C, Stephenson L, Warren E, Smith E, et al. (2015) Developing a theoretical maintenance model for disordered eating in Type 1 diabetes. Diabet Med 32(12): 1541-1545.

21. American Diabetes Association [ADA] (2016b) Obesity Management for the Treatment of Type 2 Diabetes. Diabetes Care 39(Suppl 1): S47-S51.

22. Peterson CM, Fischer S, Young Hyman D (2015) Topical review: a comprehensive risk model for disordered eating in youth with type 1 diabetes. J Pediatr Psychol 40(4): 385-390.

23. Markowitz JT, Butler DA, Volkening LK, Antisdel JE, Anderson BJ, et al. (2010) Brief screening tool for disordered eating in diabetes: internal consistency and external validity in a contemporary sample of pediatric patients with type 1 diabetes. Diabetes Care 33(3): 495-500.

\begin{tabular}{|l|}
\hline \multicolumn{1}{|c|}{ Your next submission with Juniper Publishers } \\
will reach you the below assets \\
- Quality Editorial service \\
- Swift Peer Review \\
- Reprints availability \\
- E-prints Service \\
- Manuscript Podcast for convenient understanding \\
- Global attainment for your research \\
- Manuscript accessibility in different formats \\
( Pdf, E-pub, Full Text, Audio) \\
- Unceasing customer service \\
Track the below URL for one-step submission \\
https://juniperpublishers.com/online-submission.php \\
\hline
\end{tabular}

